archives

of thermodynamics

Vol. 38(2017), No. 2, 3-20

DOI: $10.1515 /$ aoter-2017-0008

\title{
Unconfined laminar nanofluid flow and heat transfer around a rotating circular cylinder in the steady regime
}

\author{
RAFIK BOUAKKAZ ${ }^{a *}$ \\ FOUZI SALHI ${ }^{b}$ \\ YACINE KHELILI ${ }^{c}$ \\ MOHAMED QUAZZAZI ${ }^{d}$ \\ KAMEL TALBI ${ }^{e}$
}

a Military Academy of Cherchell, Tipaza, Algérie

${ }^{b}$ Université Mouloud Mammeri Tizi ouzou, Département de Génie Mécanique, Algérie

c University Saad Dahlab, Department of Mechanical Engineering, Blida 1, Algeria

$d$ Université Kasdi Merbah Ouargla, Département de Génie Mécanique, Algérie

e Université Constantine 1, Département de Génie Mécanique, Constantine, Algérie

\begin{abstract}
In this work, steady flow-field and heat transfer through a copper-water nanofluid around a rotating circular cylinder with a constant nondimensional rotation rate $\alpha$ varying from 0 to 5 was investigated for Reynolds numbers of $5-40$. Furthermore, the range of nanoparticle volume fractions considered is $0-5 \%$. The effect of volume fraction of nanoparticles on the fluid flow and heat transfer characteristics are carried out by using a finite-volume method based commercial computational fluid dynamics solver. The variation of the local and the average Nusselt numbers with Reynolds number, volume fractions, and rotation rate are presented for the range of conditions. The average Nusselt number is found to decrease with increasing value of the rotation rate for the fixed value of the Reynolds num-
\end{abstract}

${ }^{*}$ Corresponding Author. Email rafik.bouakkaz@gmail.com 
ber and volume fraction of nanoparticles. In addition, rotation can be used as a drag reduction technique.

Keywords: Nanofluid; Rotating circular cylinder; Forced convection; Steady regime

\section{Nomenclature}

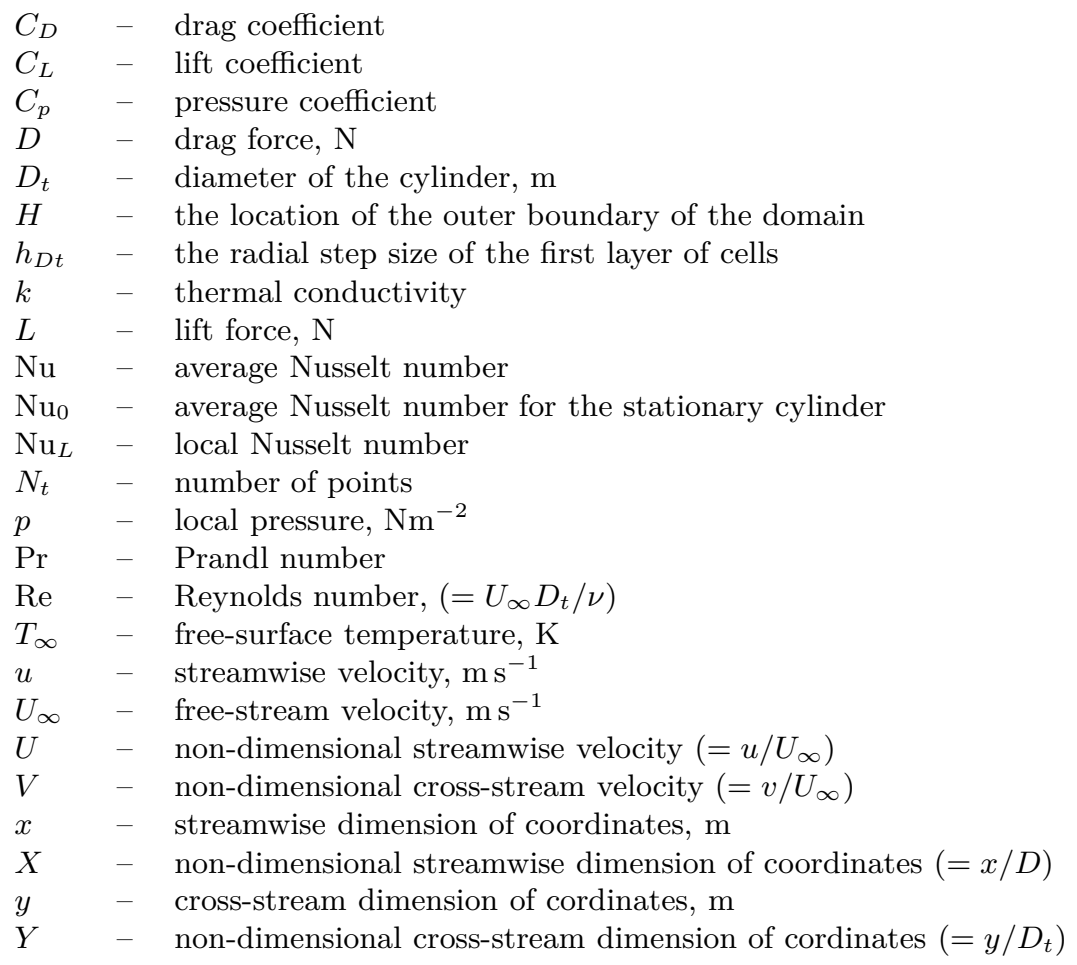

\section{Greek symbols}

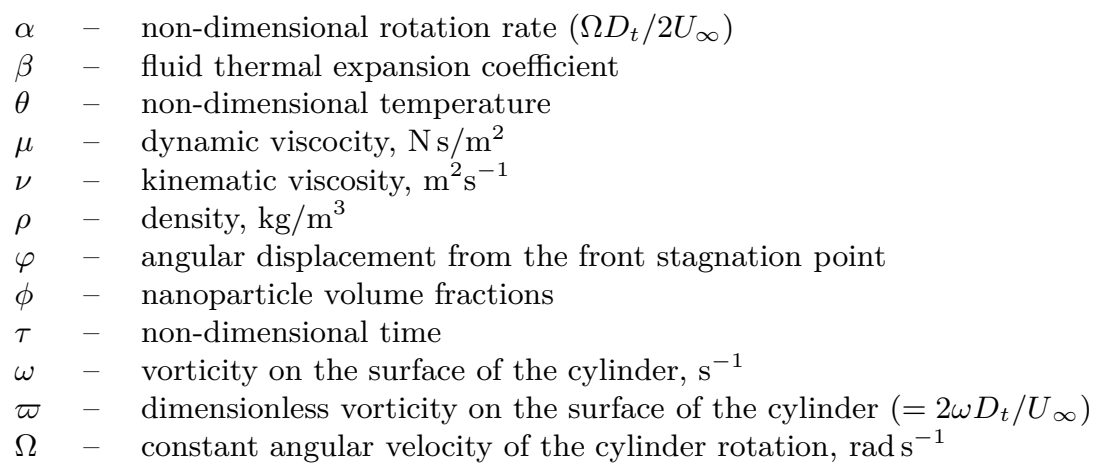

\section{Subscripts}

$n f \quad-\quad$ nanofluid 
bf $\quad-\quad$ base fluid

$s \quad-$ solid nanoparticles

\section{Introduction}

The fluid flow and heat transfer around a rotating circular cylinder are considered to be fundamental fluid mechanics problems with a huge number of practical applications such as cooling devices in plastics and glass industries, chemical processing industries and food processing. In these flows, the results depend not only on the Reynolds number, Re, but also on rotation rate, $\alpha$, defined as the ratio of rotational velocity of the cylinder wall to the incoming free stream flow velocity, expressed as: $\operatorname{Re}=U_{\infty} D_{t} / v$ and $\alpha=\Omega D_{t} / 2 U_{\infty}$.

In recent years, many researches have been performed to study the effects of rotation rate on the flow and convective heat transfer. The authors of the paper [1] investigated numerically the effect of rotation rate on the flow and heat transfer across a rotating cylinder in the range $0 \leq \alpha \leq 6$ with Re number varying in the range 20-160. They concluded that the rotation can be used as a drag reduction and heat transfer suppression technique. Subsequently, [2] studied numerically the free stream flow and forced convection heat transfer across a rotating cylinder, dissipating heat flux for Reynolds numbers of 20-160 and a Prandtl number of 0.7. Their results show that, at higher rotational velocity, the Nusselt number is almost independent of Reynolds number and thermal boundary conditions. The suppression of von Karman Street was also reported numerically in [3] for Reynolds numbers of $80-160$ and rotation rate was examined up to a maximum value of 5.3 in the range of $0-6$ at $\operatorname{Pr}$ equal 7 . For steady regime, a well-organized numerical study was published in [4]. In that paper, the numerical calculations were solved via the finite volume method in order to examine the characteristics of flow and heat transfer for varying rotation rate $(\alpha=0-5)$ in the Reynolds number range 1-35 and Prandtl numbers range $0.7-100$. They found that the average Nusselt number increases with increasing Prandtl number for the fixed value of the Reynolds number for the particular value of rotation rate.

In past studies, the fluids used have a low value of thermal conductivity, which limits the heat transfer. For this reason, there are several methods to improve the heat transfer characteristics, which consist in adding high conducting solid particles to the base fluid. The resulting fluid is called the 'nanofluid' [5-8]. 
The steady flow-field and heat transfer through a copper-water nanofluid around circular cylinder was numerically simulated by Valipour and Ghadi [9]. The values of vorticity, pressure coefficient, recirculation length are increased by the addition of nanoparticles into the base fluid. Subsequently, El-Bashbeshy et al. examined the effect of heat treatment process with a new cooling medium (nanofluid), which contains water with $\mathrm{Cu}, \mathrm{Ag}$, or $\mathrm{Al}_{2} \mathrm{O}_{3}$ particles, on heat transfer characteristics and mechanical properties of an unsteady continuous moving cylinder in the action of thermal forces [10]. They reported that the $\mathrm{Al}_{2} \mathrm{O}_{3}$ nanofluid is the best type of nanofluid for improving the mechanical properties of the surface (increase the heat flux). This nanofluid is also the best type for decreasing the surface shear stress.

Recently, numerical study has been focused on heat transfer phenomena over an isothermal cylinder, for low Reynolds number flow of nanofluid [11]. Heat transfer characteristic and flow over the stationary cylinder has been studied for water based copper nanofluid with different solid fraction values. It has been shown that the presence of nanoparticle has no effect on the point of flow separation for a fixed Reynolds number, howener, the effect of buoyancy force has not been taken into consideration. On the other hand, the momentum and forced convection heat transfer for a laminar and steady free stream flow of nanofluids past a square cylinder have been studied [12]. Different nanofluids consisting of $\mathrm{Al}_{2} \mathrm{O}_{3}$ and $\mathrm{CuO}$ with base fluids of water and a 60:40 (by mass) ethylene glycol and water mixture were selected to evaluate their superiority over conventional fluids. It has been showed that for any given particle diameter there is an optimum value of particle concentration that results in the highest heat transfer coefficient. The fluid flow and heat transfer around a square cylinder utilizing $\mathrm{Al}_{2} \mathrm{O}_{3}-\mathrm{H}_{2} \mathrm{O}$ nanofluid over low Reynolds numbers varied within the range from 1 to 40 and the volume fraction of nanoparticles is varied within the range of $0<\phi<0.05$ was investigated [13]. They found that increase of the nanoparticles volume fractions augments the drag coefficient. Moreover, pressure coefficient increases by increasing the solid volume fraction for sides where pressure gradient is inverse but for sides where the pressure gradient is favourable the pressure coefficient decreases.

The present investigation had been motivated by increased interest and research in potential improvements in heat transfer characteristics using nanofluids. Effort has been made to investigate numerically the steady flow of nanofluid and heat transfer characteristics of a rotating circular cylinder 
for a range of Reynolds numbers $(5 \leq \mathrm{Re} \leq 40)$ and particle volumetric concentrations ranging from $0 \%$ to $5 \%$ for rotation parameters $(0 \leq \alpha \leq 5)$ in the two-dimensional laminar flow regime.

\section{Problem statement, governing equations, and boundary conditions}

The system here consists of a 2D infinitely long circular cylinder having a diameter $D_{t}$ which is maintained at a constant temperature $T_{w}$ and is rotating in a counter clockwise direction with a constant angular velocity of $\Omega$. It is exposed to a constant free stream velocity of $U_{\infty}$ at a uniform temperature of $T_{\infty}$ at the inlet. The nanoparticles are assumed to be of the uniform shape and size. In addition, we have assumed that nanoparticles are in thermal equilibrium state and flowing at the same velocity. Flow configuration is shown in Fig. 1.
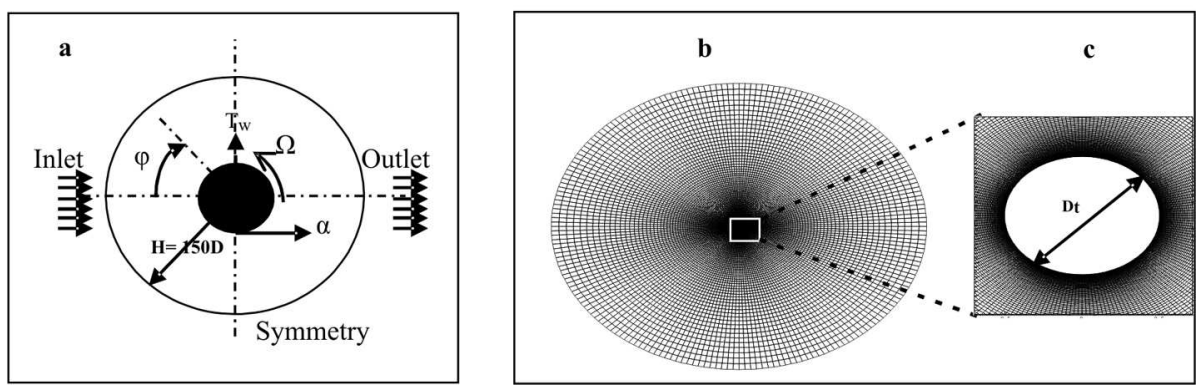

Figure 1: Schematic of the unconfined flow and heat transfer around a rotating circular cylinder (a), grid structure (b), close up view in the vicinity of the cylinder (c).

\subsection{Governing equations and boundary conditions}

The governing partial differential equations here are the Navier-Stokes and energy equations in two dimensions and steady state nanofluid flow around a rotating circular cylinder in dimensionless form are given form:

$$
\begin{gathered}
\frac{\partial U}{\partial X}+\frac{\partial V}{\partial Y}=0 \\
U \frac{\partial U}{\partial X}+V \frac{\partial U}{\partial Y}=\frac{1}{\rho_{n f}}\left[-\frac{\partial P}{\partial X}+\mu_{n f}\left(\frac{\partial^{2} U}{\partial X^{2}}+\frac{\partial^{2} U}{\partial Y^{2}}\right)\right]
\end{gathered}
$$




$$
\begin{gathered}
U \frac{\partial V}{\partial X}+V \frac{\partial V}{\partial Y}=\frac{1}{\rho_{n f}}\left[-\frac{\partial P}{\partial Y}+\mu_{n f}\left(\frac{\partial^{2} V}{\partial X^{2}}+\frac{\partial^{2} V}{\partial Y^{2}}\right)\right] \\
U \frac{\partial T}{\partial x}+V \frac{\partial T}{\partial y}=\alpha_{n f}\left(\frac{\partial^{2} T}{\partial x^{2}}+\frac{\partial^{2} T}{\partial y^{2}}\right)
\end{gathered}
$$

where: $U=\frac{u}{U_{\infty}}, V=\frac{v}{U_{\infty}}, \tau=\frac{t U_{\infty}}{D_{t}}, X=\frac{x}{D_{t}}, Y=\frac{y}{D_{t}}, P=\frac{p}{\rho U_{\infty}^{2}}, \theta=\frac{T-T_{\infty}}{T_{W}-T_{\infty}}$. Here $U$ and $V$ are the velocity components along $X$ and $Y$ axes, $T$ denotes the temperature, $P$ is the pressure, $\rho$ is the density, $\mu$ - the dynamic viscosity. The subscript $n f$ stands for the nanofluid.

The thermophysical properties taken from [9], for the base fluid and copper oxide (at $300 \mathrm{~K}$ ) are shown in Tab. 1.

Table 1: Thermophysical properties of the base fluid and cooper nanoparticles.

\begin{tabular}{|c|c|c|c|}
\hline Property & Unit & Water & Copper \\
\hline \hline$C_{p}$ & $\left(\mathrm{~J} \mathrm{~kg}^{-1} \mathrm{~K}^{-1}\right)$ & 4179 & 385 \\
\hline$\rho$ & $\left(\mathrm{kg} \mathrm{m}^{-3}\right)$ & 997.1 & 8.933 \\
\hline$k$ & $\left.\mathrm{Wm}^{-1} \mathrm{~K}^{-1}\right)$ & 0.613 & 401 \\
\hline$\alpha \times 10^{7}$ & $\left(\mathrm{~m}^{2} \mathrm{~s}^{-1}\right)$ & 1.47 & 1.163 \\
\hline
\end{tabular}

The effective density, thermal diffusivity, heat capacitance, and thermal expansion coefficient of the nanofluid are calculated using the following expressions:

$$
\begin{gathered}
\rho_{n f}=(1-\phi) \rho_{b f}+\phi \rho_{s} \\
\left(\rho C_{p}\right)_{n f}=(1-\phi)\left(\rho C_{p}\right)_{b f}+\phi\left(\rho C_{p}\right)_{s}, \\
\alpha_{n f}=\frac{k_{n f}}{\left(\rho C_{p}\right)_{n f}}, \\
\beta_{n f}=(1-\phi)(\rho \beta)_{b f}+\phi(\rho \beta)_{s},
\end{gathered}
$$

where $\phi$ is the solid volume fraction, $\alpha$ is the non-dimensional rotation rate, $\beta$ is the fluid thermal expansion coefficient, and $C_{p}$ is the pressure coefficient. Subscript bf stands for base fluid and the subscript $s$ stands for solid nanoparticles. The effective dynamic viscosity of the nanofluid is calculated using the formula suggested in [6]

$$
\mu_{n f}=\frac{\mu_{b f}}{(1-\phi)^{2.5}} .
$$


The effective thermal conductivity of the nanofluid is approximated by the Maxwell-Garnett model, for a suspension of spherical nanoparticles in the base fluid, the formula suggested by [14] is applied:

$$
k_{n f}=k_{b f}\left[\frac{\left(k_{s}+2 k_{b f}\right)-2 \phi\left(k_{b f}-k_{s}\right)}{\left(k_{s}+2 k_{b f}\right)+\phi\left(k_{b f}-k_{s}\right)}\right] .
$$

\subsection{Boundary conditions}

The dimensionless boundary conditions for the flow across a rotating circular cylinder can be written as (Fig. 1). The left-hand arc (Fig. 1a) is the inflow section or upstream section, where there is a Dirichlet-type boundary condition for the Cartesian velocity components

$$
V=0 \text { and } \theta=0,
$$

where $\theta$ is the non-dimensional temperature. The right-hand arc represents the outflow boundary, where it is considered that the diffusion flux in the direction normal to the exit surface is zero for all variables

$$
\frac{\partial U}{\partial X}=\frac{\partial V}{\partial X}=\frac{\partial \theta}{\partial X}=0 \text {. }
$$

Finally, the dimensionless peripheral or tangential velocity is prescribed on the surface of the rotating cylinder, along with a no-slip boundary condition

$$
U=-\alpha \sin (\varphi) ; \quad V=-\alpha \cos (\varphi), \quad \theta=1,
$$

where $\varphi$ is the angular displacement from the front stagnation point.

\section{$2.3 \quad$ Force coefficients}

Two relevant parameters computed from the velocity and pressure fields are the drag and lift coefficients, which represent dimensionless expressions of the forces that the fluid produces on the circular cylinder. These are defined, respectively, as follows:

$$
C_{D}=\frac{D}{\rho U_{\infty}^{2} D_{t}}, \quad C_{L}=\frac{L}{\rho U_{\infty}^{2} D_{t}},
$$

where $D$ is the drag force and $L$ is the lift force with respect to the centre of the cylinder. 


\section{$3 \quad$ Numerical details}

The computational grid for the problem under consideration was generated by using a commercial grid generator Gambit [19] and the numerical calculations were performed in the full computational domain using Fluent [20] for varying conditions of Re number and rotation rate. This computer program applies a control-volume method to integrate the equations of motion, constructing a set of discrete algebraic equations with conservative properties. In particular, the O-type grid structure similar to that adopted in [15] was created here. The steady, laminar, segregated solver was employed here to solve the incompressible flow on the collocated grid arrangement. Semi implicit method for the pressure linked equations (SIMPLE) [4] was used to solve Navier-Stokes and energy equations for above noted boundary conditions. Second order upwind scheme is used to discretize the convective terms of momentum equations, whereas the diffusive terms are discretized by the central difference method. A convergence criterion of $10^{-8}$ is used for continuity, and Cartesian components components of momentum equations, while for energy equation the criterion of convergence was $10^{-10}$.

\subsection{Domain independence study}

The mesh used for all the two-dimensional computations consisted of 40000 quadrilateral cells and 40200 nodes. The cylinder (of diameter $D_{t}$ ) resides in a computational domain whose outer edges located at a distance of $H$ from the centre of the cylinder (see Fig. 1). There are $N_{t}$ points in the circumferential direction on the cylinder surface and the radial thickness of the first layer of cells (i.e., cells attached to the wall) is $h_{D t}$. A close-up view of a typical mesh is shown in Fig. 1c. It can be observed that the mesh is very fine close to the cylinder and the cells become larger with increasing distance from the cylinder. The location of the outer boundary of the domain is expected to become more crucial for larger values of $\alpha[16,17]$. In this study, following [4], the computational domain covers 150 times the diameter of the cylinder in all directions. The grid sensitivity analysis was performed for $\operatorname{Re}=40$ and $\phi=0.05$. Table 2 lists the details for the meshes that were employed. Bearing in mind the influence of the number of grid points on the average Nusselt number on the cylinder wall, it was decided to carry out computations with mesh M2. 
Table 2: Effect of grid number on averaged Nusselt number $(\mathrm{Nu})$ at $\mathrm{Re}=40, \mathrm{Pr}=6.264$ $(\phi=0.05)$ for $\alpha=0$ and $\alpha=5$.

\begin{tabular}{|c|c|c|c|c|c|}
\hline \multirow{2}{*}{ Mesh } & \multirow{2}{*}{ Cells } & \multirow{2}{*}{$N t$} & \multirow{2}{*}{$h_{D t}$} & \multicolumn{2}{|c|}{ Nu } \\
\cline { 5 - 6 } & & & & $\alpha=0$ & $\alpha=5$ \\
\hline \hline $\mathrm{M} 1$ & 32000 & 160 & 0.0015 & 7.5880 & 4.6222 \\
\hline $\mathrm{M} 2$ & 40000 & 200 & 0.0010 & 7.6139 & 4.6464 \\
\hline $\mathrm{M} 3$ & 50000 & 250 & 0.0010 & 7.6 .76 & 4.6495 \\
\hline
\end{tabular}

\section{Results and discussion}

\subsection{Comparison with other results}

The first step was to validate the problem set-up, the choice of numerical methods and mesh attributes by comparing results from our numerical simulations with results obtained from the literature. The outcomes included in the comparison were the mean Nusselt number, as well as lift and drag coefficients.

The average Nusselt number for stationary cylinder at $\mathrm{Re}=40$ (base fluid) and $\phi=0.05(\operatorname{Pr}=6.26)$, is found to be in good agreement with the correlation [18].

$$
\mathrm{Nu}=0.593 \operatorname{Re}^{1 / 2} \operatorname{Pr}^{1 / 3}
$$

Using this relation for same parameters, the value of the average Nusselt number $\mathrm{Nu}=7.66$ is obtained, which is in excellent agreement with present calculations, $\mathrm{Nu}=7.61$.

It is interesting to remind that the Reynolds and Prandtl number of nanofluids can be expressed as

$$
\operatorname{Re}_{n f}=\frac{\rho_{n f}}{\rho_{b f}} \frac{\mu_{b f}}{\mu_{n f}} \operatorname{Re}_{b f}, \quad \operatorname{Pr}_{n f}=\frac{\mu_{n f}}{\mu_{b f}} \frac{C_{P, n f}}{C_{P, b f}} \frac{k_{b f}}{k_{n f}} \operatorname{Pr}_{b f}
$$

Comparison of the average Nusselt number results for a rotating circular cylinder under different Reynolds numbers with data from [1] is given in Tab. 3. The present results of the average $\mathrm{Nu}$ number are in excellent agreement with the literature ones.

Table 4 compares the lift and drag coefficients computed here with results cited in scientific publications. We have noted that the lift coefficient 
values are in superb agreement with numerical data reported by other researchers, but discrepancies in the values of the drag coefficient are larger; the drag coefficients are so small that the relative errors are magnified.

Table 3: Comparison of Nusselt number computed in the present study with literature data $(\operatorname{Pr}=0.7)$.

\begin{tabular}{|c|c|c|c|c|}
\hline \multirow{2}{*}{$\mathrm{Re}$} & \multirow{2}{*}{$\alpha$} & \multicolumn{2}{|c|}{$\mathrm{Nu}$} & \multirow{2}{*}{$\begin{array}{l}\text { Relative } \\
\text { error }(\%)\end{array}$} \\
\hline & & Present study & Paper[1] & \\
\hline 20 & 0 & 2.4092 & 2.4189 & 0.40 \\
\hline 20 & 2 & 2.2785 & 2.2861 & 0.33 \\
\hline 20 & 4 & 2.2511 & 2.2554 & 0.19 \\
\hline 40 & 0 & 3.2496 & 3.2465 & 0.10 \\
\hline 40 & 2 & 3.0402 & 3.0115 & 0.95 \\
\hline 40 & 4 & 3.0614 & 3.0422 & 0.63 \\
\hline
\end{tabular}

Table 4: Comparison between the lift and drag coefficients computed in the present study with values given by literature data.

\begin{tabular}{|c|c|c|c|c|c|c|c|}
\hline \multicolumn{2}{|c|}{ Re } & \multicolumn{3}{c|}{$C_{D}$} & \multicolumn{3}{c|}{$C_{L}$} \\
\hline Re & $\alpha$ & $\begin{array}{c}\text { Present } \\
\text { study }\end{array}$ & $\begin{array}{c}\text { Paper } \\
{[1]}\end{array}$ & $\begin{array}{c}\text { Relative } \\
\text { error (\%) }\end{array}$ & $\begin{array}{c}\text { Present } \\
\text { study }\end{array}$ & $\begin{array}{c}\text { Paper } \\
{[1]}\end{array}$ & $\begin{array}{c}\text { Relative } \\
\text { error (\%) }\end{array}$ \\
\hline \hline 40 & 0 & 1.503 & 1.504 & 0.066 & 0 & 0 & 0 \\
\hline 40 & 1 & 1.3132 & 1.315 & 0.15 & -2.5817 & -2.6013 & 0.75 \\
\hline 40 & 4 & -0.038 & -0.052 & 26.92 & -16.083 & -16.033 & 0.31 \\
\hline
\end{tabular}

\subsection{Mean lift and drag coefficients}

Figure 2 shows that the negative/downward lift coefficient, $C_{L}$, increases monotonically with increasing $\alpha$ and with increasing Re. However, the increase is marginal with increasing Re. Thus, the lift coefficient is strongly dependent on the rotation rate and weakly dependent on Re. Very high lift coefficients are observed for high rotation rates of the cylinder. 


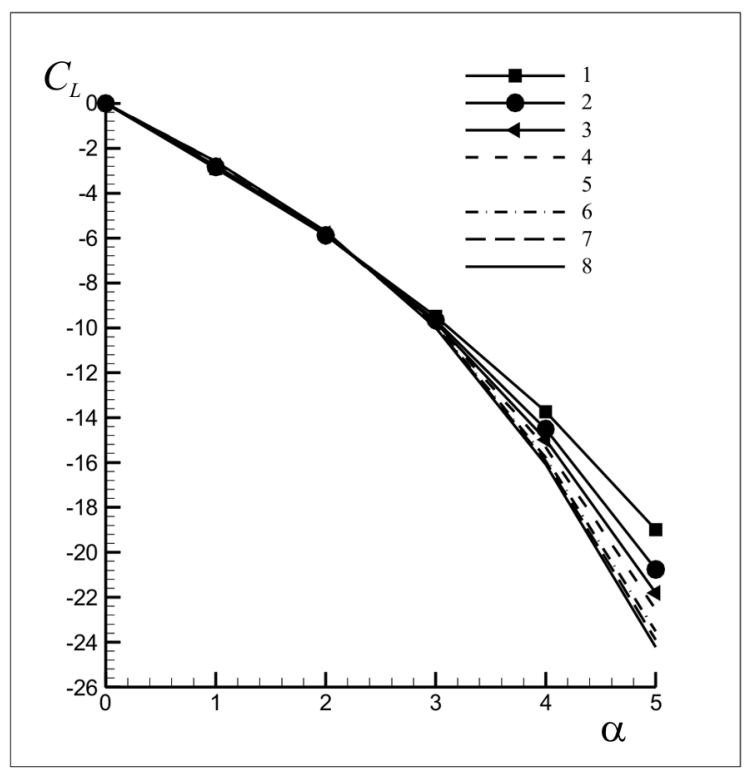

Figure 2: Variation of mean lift coefficient, $C_{L}$, with rotation rate, $\alpha$, for various Reynolds number; $\operatorname{Re}=5$ (1), 10 (2), 15 (3), 20 (4), 25 (5), 30(6), 35 (7), 40 (8).

Figure 3 shows the variation of the drag coefficient, $C_{D}$, with rotation rate $0 \leq \alpha \leq 5$ for $\operatorname{Re}=5,10,15,20,25,30,35$, and 40 . It can be noted that with the increase in rotation rate, drag coefficient values for all the Reynolds number converge at approximately the same value for $\alpha$ of 5 with the exception of Re equal to 5 and 10.

\subsection{Isotherm patterns}

The isotherms profiles around the rotating cylinder for Reynolds number of 20 and 40 for $\alpha$ of 0 and 5 are compared between the base fluid and nanofluid $(\phi=0.05)$ in Fig. 4a. Clearly, the temperature distribution contours for base fluid are overlaid with that for nanofluid. This can be explained by the fact that the addition of solid particles to the base-fluid increases the Reynolds number of nanofluid. Hence results the higher capacity of transferring the heat from the cylinder. For a stationary cylinder, it is obvious from Fig. 4a that the isotherms have maximum density close to the front surface of the cylinder; this indicates high values of the local Nusselt number near the front stagnation point on the front surface as compared to other points on the cylinder surface. On other hand, as the 


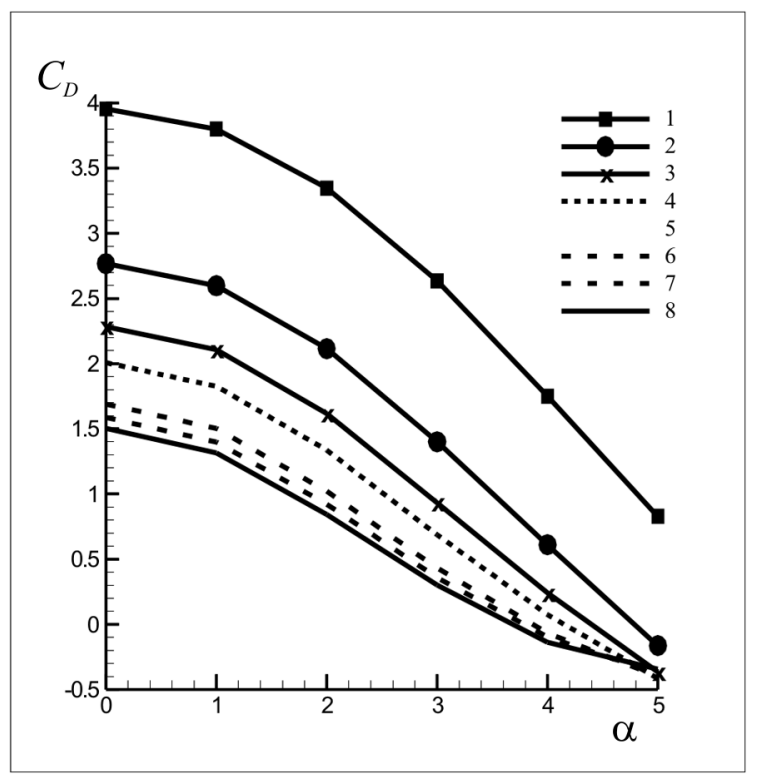

Figure 3: Variation of mean drag coefficient, $C_{D}$, with rotation rate, $\alpha$, for various Reynolds number. For legend see page 13.

Re increase, the recirculation region behind the cylinder grows yields to increase in the density of isotherms close to the rear surface as shown in Fig. 4b. On increasing the value of the rotation rate, the maximum density of the isotherm shifts from the front surface towards the bottom surface of the rotating cylinder (rotating counter clockwise), Fig. 4c. In addition, as the solid concentration, $\phi$, increases, the thermal boundary layer becomes thinner which leads to the increase in the Nusselt number, Fig. $4 \mathrm{~d}$.

\subsection{Local Nusselt number}

Figure 5 shows the variation of local Nusselt number, $\mathrm{Nu}_{L}$, on the surface of the cylinder with increase in Reynolds number, Re, for various rotation rates, $\alpha$, and volume fraction, $\phi$. When the solid concentration increases the thermal conductivity improves and consequently the local Nusselt number increase. Additionally, the thermal boundary layer is decreased by any increase in the solid volume fraction (Fig. 4). Therefore, the local Nusselt number is enhanced by any increase in solid volume fraction. On the other hand, for a stationary cylinder and for all Re, the variation of $\mathrm{Nu}_{L}$ is found to be symmetrical at $\varphi=180^{\circ}$. The value of the local $\mathrm{Nu}$ number is 

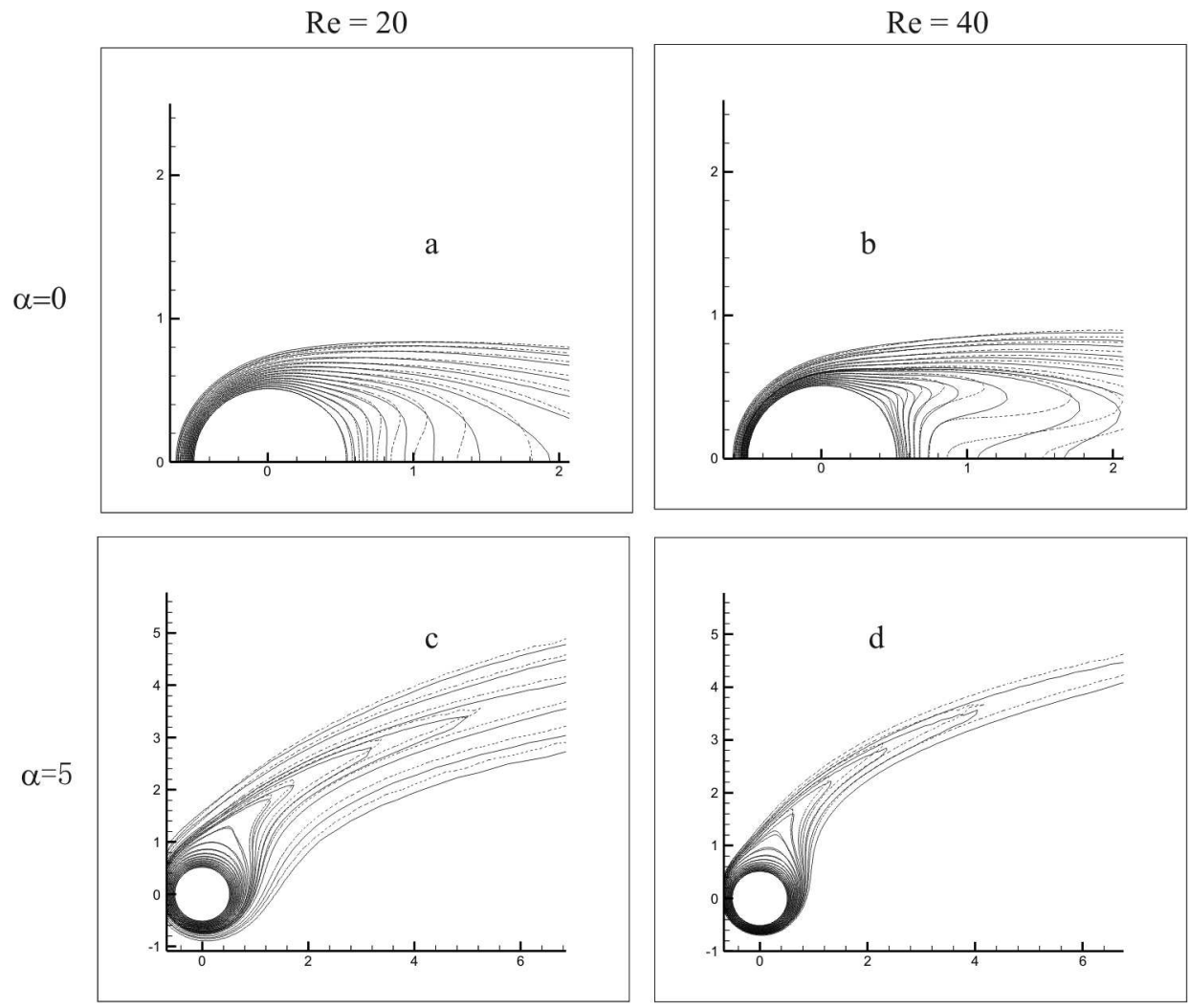

Figure 4: Temperature contours for the flow around the cylinder (solid line refers to base fluid and dashed line refers to nanofluid with solid volume fraction 0.05) at: (a) $\operatorname{Re}=20, \alpha=0, \phi=0$; (b) $\operatorname{Re}=20 \alpha=0, \phi=0.05$; (c) $\operatorname{Re}=20, \alpha=5$, $\phi=0$; (d) $\operatorname{Re}=40, \alpha=5, \phi=0.05$.

maximum on the front $(\varphi=0)$ and minimum on the rear $\left(\varphi=180^{\circ}\right)$ side of the cylinder. Also, at this former angle, a kink is observed in the values of local Nusselt number and the size of this kink increases as the value of the Re number increases for the fixed value of $\phi$. It can be explained on the basis that higher Reynolds number results in larger recirculation region. Also, the symmetrical variation of $\mathrm{Nu}_{L}$ seen in the figures for $\alpha=0$ is lost under the effect of rotation. On increasing the value of the rotation rate, the local $\mathrm{Nu}$ number curve becomes smooth and the kink disappears. Finally, the rotation causes overall reduction in heat transfer across the cylinder, thus lowering the local Nusselt number at higher rotations. 


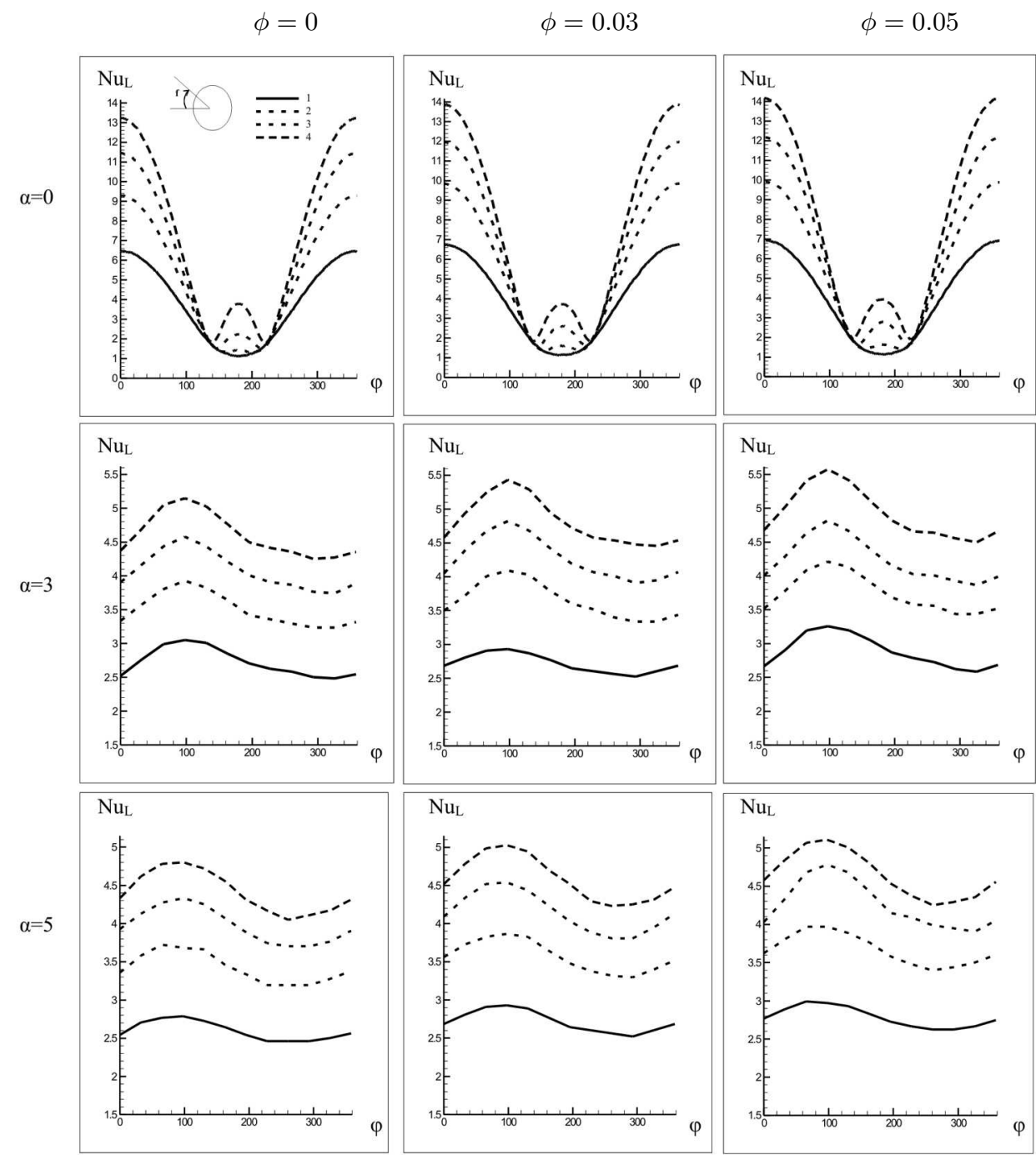

Figure 5: Local Nusselt number variation at various solid volume fractions for varying values of Reynolds number and rotation rate: $\operatorname{Re}=10$ (1), 20 (2), 30 (3), 40 (4).

\subsection{Averaged Nusselt number}

Figure 6 indicates that the averaged Nusselt number increases monotonically with increasing Re at constant $\alpha$ for a fixed volume fraction of nanoparticles, $\phi$. This can be explained as when Reynolds number in- 
$\phi=0$

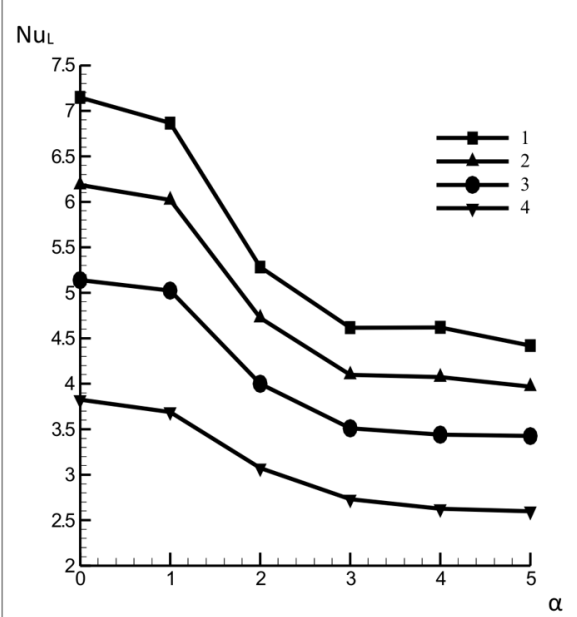

$\mathrm{Nu}$

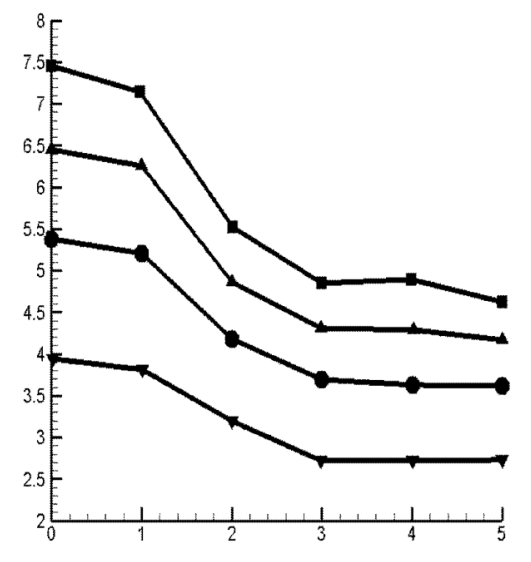

$\phi=0.03$ $\phi=0.01$

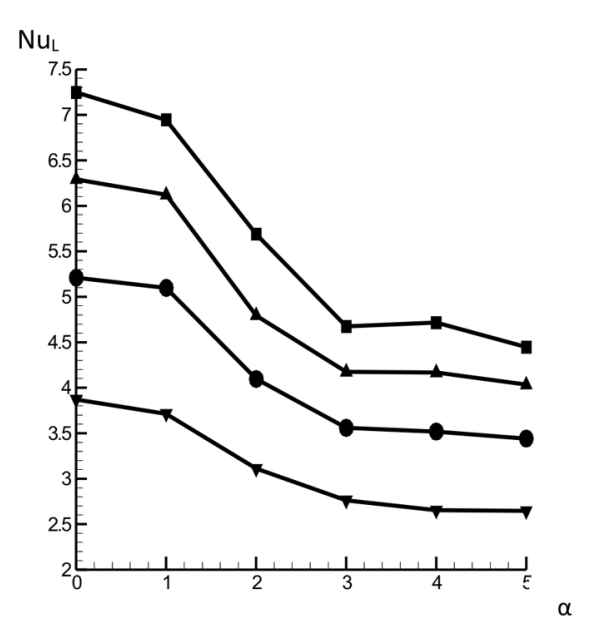

$\mathrm{Nu}_{\mathrm{L}}$

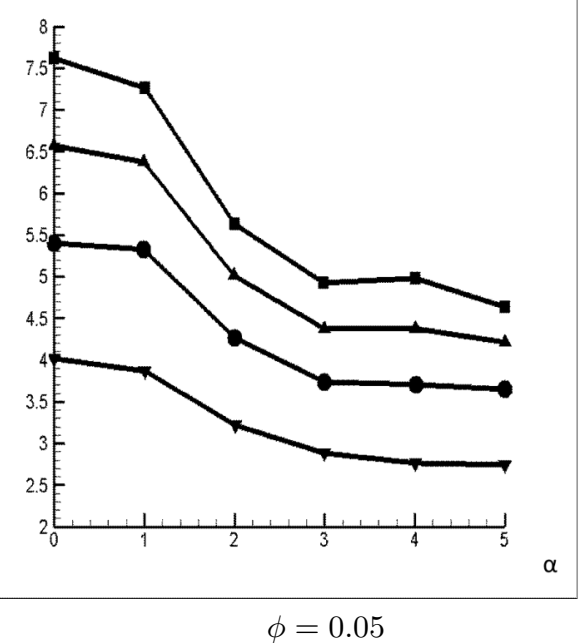

Figure 6: Variation of local Nusselt number with increasing Reynolds number for various rotation rates at various solid volume fractions: $R e=40$ (1), 30 (2), 20 (3), $10(4)$.

creases the inertia of flow increases thus increasing the heat transfer. The effect of Reynolds number also increases with increase in volume fraction number. Considering the case of the static cylinder, the change in average Nusselt number at volume fraction of 0 when Reynolds number increases 
from 5 to 40 is 4.409 . While the corresponding change in average Nusselt number due to increase in Reynolds number for volume fraction of 0.05 is 4.220. Further increase in rotation rate, for the fixed value of volume fraction, the value of the average Nusselt number decreases for all Reynolds numbers. The decrease in the Nusselt number with increasing rotational velocity can be explained on the basis that the fluid entrapped inside the enveloping vortex acts as a buffer zone for heat transfer between the cylinder and free stream and restrict the heat transfer to conduction only as detailed in [1].

$\phi=0$

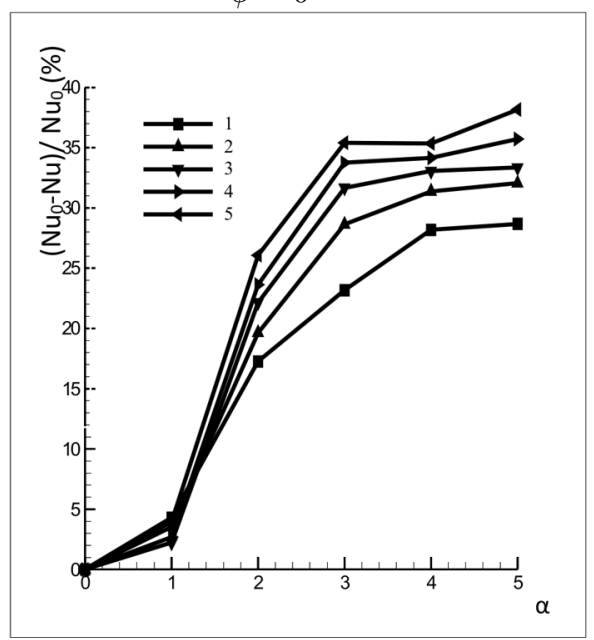

$\phi=0.05$

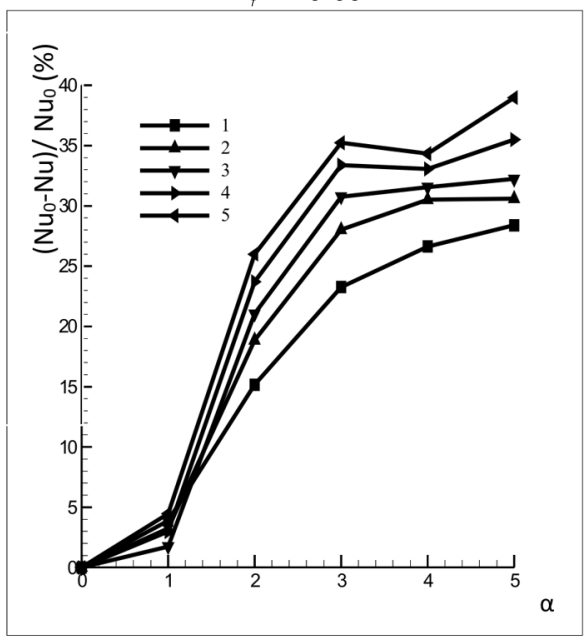

Figure 7: Percentage heat transfer suppression with increasing Reynolds number for various rotation rates. $\mathrm{Nu}_{0}$ is the Nusselt number of the stationary cylinder: $\operatorname{Re}=5$ (1), 10 (2), 20 (3), 30 (4), 40 (5).

Figure 7 shows the normalized Nusselt number obtained as the ratio of average Nusselt number of the rotating cylinder, $\mathrm{Nu}$, to that of the stationary cylinder, $\mathrm{Nu}_{0}$, for base fluid and nanofluid $(\phi=0.05)$ at various rotation rates, $\alpha$, to understand the suppression of heat transfer. For $\phi$ of 0 , it can be seen from this figure that the suppression increases with increasing $\operatorname{Re}$ and increasing $\alpha$, with a minimum value of $4.30 \%$ for $\operatorname{Re}=5$ and a maximum value of $38.17 \%$ for $\operatorname{Re}=40$ at $\alpha=5$. Thus, cylinder rotation can be used not only for controlling flow, but also as an efficient heat transfer suppression technique. Moreover, for the case $\phi=0.05$, the 
suppression curves remain practically similar. This can be explained that the Prandlt number is nearly the same: the change in the value of the Prandtl for the case $\phi=0$ is in the range from 7.066 to 6.264 for the case $\phi=0.05$. Hence, the suppression of heat transfer is not enhanced due to adding nanoparticles into the base fluid.

\section{Conclusions}

The present study focuses on the unconfined laminar flow of nanofluid and heat transfer characteristics around a rotating circular cylinder subjected to constant wall temperature. Heat transfer suppression due to rotation increases with increasing Reynolds number and increasing rotation rate. Moreover, the heat transfer suppression is not enhanced due to adding nanoparticles into the base fluid. Also, a downward drag coefficient is found due to rotation, which decreases monotonically with increasing rotation rate. Thus, rotation can be used as a drag reduction technique.

Further, the average Nusselt number is found to decrease with increasing rotation rate and increase with increasing Reynolds number . Suppression due to rotation increases with increasing Reynolds number and increasing rotation rate for all Reynolds number .

Received 12 October 2016

\section{References}

[1] Paramane S.B., Sharma A.: Numerical investigation of heat and fluid flow across a rotating circular cylinder maintained at constant temperature in $2 D$ laminar flow regime. Int. J. Heat Mass Tran. 52(2009), 13-14, 3205-3216.

[2] Paramane S.B., Sharma A.: Heat and fluid flow across a rotating cylinder dissipating uniform heat flux in 2D laminar flow regime. Int. J. Heat Mass Tran. 53(2010), 21-22, 4672-4683.

[3] Sufyan M., Manzoor S., Sheikh N.A.: Heat transfer suppression in flow around a rotating circular cylinder at high Prandtl number. Arab. J. Sci. Eng. 39(2014), 11, 8051-8063.

[4] Sharma V., Dhiman A.K.: Heat transfer from a rotating circular cylinder in the steady regime: Effects of Prandtl number. Thermal Sci. 16(2012), 1, 79-91.

[5] Sarit K. Das, Stephen U. Choi, Wenhua Yu, T. Pradeep: Nanofluids: Science and Technology. Wiley, New York 2007.

[6] Brinkman H.C.: The viscosity of concentrated suspensions and solutions. J. Chem. Phys. 20(1952), 4, 571-581. 
[7] Chang H., Jwo C.S., Lo C.H., Tsung T.T., KaO M.J., Lin H.M.: Rheology of CuO nanoparticle suspension prepared by ASNSS. Rev. Adv. Mater. Sci. 10(2005), $2,128-132$.

[8] Cieśliński J.T., Ronewicz K., Smoleń S.: Measurement of temperaturedependent viscosity and thermal conductivity of alumina and titania thermal oil nanofluids. Arch. Thermodyn. 36(2015), 4, 35-47.

[9] VAlipour M.S., GHAdi A.Z.: Numerical investigation of fluid flow and heat transfer around a solid circular cylinder utilizing nanofluid. Int. Commun. Heat Mass 38(2011), 9, 1296-1304

[10] El-Bashbeshy E.S.M.A , Emam T.G., Abdel-Wahed M.S.: The effect of thermal radiation, heat generation and suction/injection on the mechanical pro properties prieties of unsteady continuous moving cylinder in a a nanofluid. Therm. Sci. 19(2015), 5, 1591-1601.

[11] Vegad M., Satadia S., Pradip P., Chirag P., Bhargav P.: Heat transfer characteristics of low Reynolds number flow of nanofluid around a heated circular cylinder. Proc. 2nd Int. Conf. Innovations in Automation and Mechatronics Engineering, ICIAME 2014, Procedia Technology 14(2014), 348-356.

[12] Farooji V.E., Bajestan E.E.,Niazmand H.,Wongwises S.: Unconfined laminar nanofluid flow and heat transfer around a square cylinder. Int. J. Heat Mass Tran. $\mathbf{5 5}(2012)$, 5-6, 1475-1485.

[13] Valipour M.S.,Masoodi R., Rashidi S., Bovand M., Mirhosseini M.: A numerical study on convection around a square cylinder using AL2O3-H2O nanofluid. Therm. Sci. 18(2014), 4, 1305-1314.

[14] Yu W., Choi S.U.S.: The role of interfacial layers in the enhanced thermal conductivity of nanofluids: A renovated Maxwell model. J. Nanopart. Res. 5(2003), 1, $167-71$.

[15] Kang S., Choi H., And Lee S.: Laminar flow past a rotating circular cylinder. Phys. Fluids 11(1999), 11, 3312-3321; DOI: http://dx.doi.org/10.1063/1.870190.

[16] Mittal S., Kumar B.: Flow past a rotating cylinder. J. Fluid Mech. 476(2003), 303-334.

[17] Padrino J.C., JosePh D.D.: Numerical study of the steady-state uniform flow past a rotating cylinder. J. Fluid Mech. 557(2006), 191-223.

[18] Stojkovic D., Breuer M., Durst F.: Effect of high rotation rates on the laminar flow around a circular cylinder. Phys. Fluids 14(2002), 9, 3160-3178.

[19] GAMBIT. Gambit User's guide V2.2, 2001.

[20] Fluent 6.3. User's guide. Fluent Inc. 2006.

[21] Bouakkaz R., Talbi K., Khelil Y., Salhi F., Belghar N., Ouazizi M.: Numerical investigation of incompressible fluid flow and heat transfer around a rotating circular cylinder. Thermophys. Aeromech. 21(2014), 1, 87-97. 